\section{ORIGINAL RESEARCH}

\section{M.T. Luetmer}

D.F. Kallmes

\title{
Have Referral Patterns for Vertebroplasty Changed since Publication of the Placebo- Controlled Trials?
}

BACKGROUND AND PURPOSE: Our aim was to determine whether referral patterns and rates of vertebroplasties at the Mayo Clinic have changed after the publication of the INVEST and the Australian Trial. In August of 2009, we performed a retrospective review of patients undergoing vertebroplasties and those patients who were referred for but did not receive vertebroplasties before and after the recently published placebo-controlled vertebroplasty trials.

MATERIALS AND METHODS: After approval by our local institutional review board, we retrospectively evaluated all patients referred for vertebroplasty between January 5, 2004, and June 2, 2010. We catalogued age, sex, number of treated vertebrae, physician referring the patient for vertebroplasty, and the referring department. We calculated the mean number of referrals per month before and after August 2009, which was the month of publication for both trials. We also calculated rates for specific referring physician types.

RESULTS: During the full study, 1188 patients were referred, of whom 807 underwent treatment at 1378 levels for a total of 943 separate vertebroplasty procedures. The mean number of vertebroplasty referrals per month has dropped significantly from $18.9 \pm 5.3(95 \% \mathrm{Cl}, 17.7-20.2)$ before publication to $11.3 \pm 3.1(95 \% \mathrm{Cl}, 9.1-13.5)$ referrals per month after publication $(P=.0001)$. Before publication, $67.3 \pm 14.0 \%(95 \% \mathrm{Cl}, 64.0 \%-70.7 \%)$ of patients referred for vertebroplasty underwent vertebroplasty, compared with $76.0 \pm 14.9 \%(95 \% \mathrm{Cl}, 65.4 \%-86.6 \%)$ after publication $(P=.11)$.

CONCLUSIONS: The number of vertebroplasty referrals at our center has decreased significantly since the publication of INVEST and the Australian Trial, yet we continue to offer the procedure to a high proportion of referred patients.

ABBREVIATIONS: $\mathrm{Cl}=$ confidence interval; INVEST = INvestigational Vertebroplasty Efficacy and Safety Trial; PMR = Physical Medicine and Rehabilitation

$S_{\text {i }}^{\text {i }}$ ince the development of spine augmentation, there has been a rapid rise in the use of vertebroplasty in the United States. Vertebroplasty and kyphoplasty combined have increased $12,900 \%$ from 1993 to 2004, and rates of vertebroplasty in Medicare enrollees nearly doubled from 2001 to 2005. ${ }^{1,2}$ Furthermore, the procedure was endorsed in 2007 by several American neurologic surgical and radiologic societies that deemed it to be a safe and effective treatment of osteoporotic and neoplastic vertebral fractures. ${ }^{3}$

Recent blinded placebo-controlled trials have cast doubt on the efficacy of vertebroplasty. ${ }^{4,5}$ Whether these publications have influenced the practice of vertebroplasty remains unknown. The purpose of this study was to determine whether referral patterns and rates of vertebroplasties at the Mayo Clinic have changed since publication of the placebo-controlled trials.

\section{Materials and Methods}

The study was approved by our local institutional review board. This retrospective study compared the number of patients who were evaluated for vertebroplasty and those treated with vertebroplasty before the publication of INVEST ${ }^{6}$ and the Australian Trial, between January 5, 2004, and August 6, 2009, with the number of patients evaluated

Received August 17, 2010; accepted after revision September 12.

From the College of Saint Benedict/Saint John's University (M.T.L.), St. Joseph, Minnesota; and Department of Radiology (D.F.K.), Mayo Clinic, Rochester, Minnesota.

Please address correspondence to David F. Kallmes, MD, Mayo Clinic, 200 First St SW, Rochester, MN 55905; e-mail: Kallmes.david@mayo.edu

DOI 10.3174/ajnr.A2371 and treated after the publication from August 7, 2009, to June 2, 2010. Patients included were those who were referred for vertebroplasty and/or received $\geq 1$ vertebroplasty between January 5, 2004, and June 2, 2010. Patients enrolled in research trials were included. A single investigator (M.T.L.) performed a chart review of patient and procedure records to evaluate age, sex, number of treated vertebrae, physician referring the patient for vertebroplasty, and the referring department. Both the evaluations leading to vertebroplasty and those not leading to vertebroplasty were grouped into months by evaluation date. A number of previous case series from our institution have been published by using some portions of this same patient data base. ${ }^{4,6}$ However, we have never previously performed a detailed analysis of referral patterns and rates of vertebroplasty.

\section{Statistical Analysis}

We compared the mean number of total referrals per month and the mean number of referrals per month by department by using the Student $t$ test. We divided the number of patients treated with vertebroplasty by the total number of those referred for vertebroplasty evaluation, and these ratios were compared pre- and post-INVEST by using the Student $t$ test.

\section{Results}

A total of 1188 patients underwent 1382 vertebroplasty evaluations during the entire study period. Eight hundred seven $(68 \%)$ of 1188 referred patients underwent treatment at 1378 vertebral levels in 943 separate vertebroplasty sessions. Six hundred eighty-nine $(85.4 \%)$ of 807 treated patients had 1 vertebroplasty session, $85(10.5 \%)$ of 807 treated patients had 


\begin{tabular}{lcc}
\hline Mean number of referrals per month from referring departments before and after publication of INVEST and the Australian Trial \\
\hline $\begin{array}{l}\text { Referring } \\
\text { Department }\end{array}$ & $\begin{array}{c}\text { Mean No. of Referrals per Month after } \\
\text { Publication }\end{array}$ & $\begin{array}{c}P \\
\text { Publication }\end{array}$ \\
\hline Spine Center and PMR & $6.3 \pm 2.8$, & $3.4 \pm 1.3$, \\
& $95 \% \mathrm{Cl}, 5.7-7.0$ & $95 \% \mathrm{Cl}, 2.4-4.4$ \\
Hematology & $2.2 \pm 1.6$, & $2.6 \pm 1.9$, \\
& $95 \% \mathrm{Cl}, 1.8-2.6$ & $95 \% \mathrm{Cl}, 1.2-4.0$ \\
Orthopedics & $1.6 \pm 1.4$, & $0.6 \pm 1.0$, \\
& $95 \% \mathrm{Cl}, 1.3-2.0$ & $95 \% \mathrm{Cl},-0.1-1.3$ \\
\hline
\end{tabular}

2 vertebroplasty sessions, 20 (2.5\%) of 807 treated patients had 3 vertebroplasty sessions, and 13 (1.6\%) of 807 treated patients had $\geq 4$ total vertebroplasty sessions (including those before January 5,2004$)$. The mean number of levels treated per session was $1.5 \pm 0.8$; median, 1 level; range, $1-6$ levels. Of those 807 patients undergoing vertebroplasty, $516(64 \%)$ were women with a mean age of $74.6 \pm 11.7$ years; median, 77 years; range, 23-96 years. Two hundred ninety-one (36\%) were men, with a mean age of $71.3 \pm 13.0$ years; median, 74.0 years; range, 32-97 years. Age was at the time of the first vertebroplasty. Of those 381 patients evaluated for but not receiving vertebroplasty, $221(58 \%)$ were women, with mean age of $73.5 \pm 13.0$ years; median, 76 years; range, $31-96$ years. One hundred sixty $(42 \%)$ of 381 were men, with mean age of $67.5 \pm 13.7$ years; median, 70 years; range, $22-97$ years. The age was at the time of the first evaluation.

The mean number of vertebroplasty referrals per month dropped significantly from $18.9 \pm 5.3$ (95\% CI, 17.7-20.2) before publication of INVEST to $11.3 \pm 3.1$ (95\% CI, 9.113.5) referrals per month after publication $(P=.0001)$. Before publication, $67.3 \pm 14.0 \%$ (95\% CI, $64.0 \%-70.7 \%)$ of patients referred for vertebroplasty were offered vertebroplasty, compared with $76.0 \pm 14.9 \%(95 \% \mathrm{CI}, 65.4 \%-86.6 \%)$ after publication $(P=.1083)$.

Referrals were received from $>20$ different departments and 420 different referring physicians. The mean number of referrals per month from the Spine Center and PMR and Orthopedics decreased significantly after the publication (Table). There was no statistically significant difference between the mean number of referrals from the Department of Hematology per month before and after the publication.

\section{Discussion}

In the current study, we found that at our single center, the number of patients referred for consideration of vertebroplasty decreased significantly after the publication of INVEST and the Australian Trial, compared with the rate of such referrals during the 5 years preceding publication of that trial. While we have not specifically queried any referring physicians regarding reasons for changing referral patterns, we believe that the relatively sudden drop in the rate of referral reflects a response to the results published in the placebocontrolled trials. Notably, we continue to offer vertebroplasty to a high proportion of referred patients, indicating that our own belief in the efficacy of the procedure outweighs its risks.

The rate of referrals from the Department of Hematology, most for patients with multiple myeloma, did not change after publication of INVEST and the Australian Trial. Because the INVEST trial specifically excluded patients with myeloma, re- ferring hematologists may believe that the results of the trial do not apply to these types of patients.

Numerous commentaries and editorials have questioned the efficacy of spine augmentation in light of the placebocontrolled trials. ${ }^{7-12}$ Even in light of the trials and commentaries, we continue to perform vertebroplasty relatively frequently. Indeed, we noted in the current study a trend toward an increase in the proportion of referred patients who undergo the procedure. This increase in the percentage of referrals leading to vertebroplasty may indicate that physicians are more stringent than previously regarding whom they refer for vertebroplasty.

\section{Conclusions}

The number of vertebroplasty referrals has decreased nearly $50 \%$ since the publication of INVEST and the Australian Trial, yet we continue to offer the procedure to a high percentage of referred patients.

\section{Acknowledgments}

We thank Arash Ehteshami Rad, MD, and Leigh A. Gray for advice regarding patient data collection, data analysis, and manuscript preparation.

\section{References}

1. Lad SP, Patil CG, Lad EM, et al. National trends in vertebral augmentation procedures for the treatment of vertebral compression fractures. Surg Neurol 2009:71:580-84, discussion 584-85

2. Gray DT, Hollingworth W, Onwudiwe N, et al. Thoracic and lumbar vertebroplasties performed in US Medicare enrollees, 2001-2005. JAMA 2007;298:1760-62

3. Jensen ME, McGraw JK, Cardella JF, et al. Position statement on percutaneous vertebral augmentation: a consensus statement developed by the American Society of Interventional and Therapeutic Neuroradiology, Society of Interventional Radiology, American Association of Neurological Surgeons/Congress of Neurological Surgeons, and American Society of Spine Radiology. AJNR Am J Neuroradiol 2007;28:1439-43

4. Kallmes DF, Comstock BA, Heagerty PJ, et al. A randomized trial of vertebroplasty for osteoporotic spinal fractures. N Engl J Med 2009;361:569-79

5. Buchbinder R, Osborne RH, Ebeling PR, et al. A randomized trial of vertebroplasty for painful osteoporotic vertebral fractures. $N$ Engl $\mathrm{J} \mathrm{Med}$ 2009;361:557-68

6. Layton KF, Thielen KR, Koch CA, et al. Vertebroplasty, first 1000 levels of a single center: evaluation of the outcomes and complications. AJNR Am J Neuroradiol 2007;28:683-89

7. Kasperk C, Meeder PJ, Noldge G, et al. Vertebroplasty and kyphoplasty: inefficient treatments for degenerative spine disease. Exp Clin Endocrinol Diabetes 2010;118:71-74

8. Gangi A, Clark WA. Have recent vertebroplasty trials changed the indications for vertebroplasty? Cardiovasc Intervent Radiol 2010;33:677-80

9. Fisher CG, Vaccaro AR, Thomas KC, et al. Evidence-based recommendations for spine surgery. Spine (Phila Pa 1976) 2010;35:E678-86

10. Weinstein JN. Balancing science and informed choice in decisions about vertebroplasty. N Engl J Med 2009;361:619-21

11. Carey TS. ACP Journal Club: vertebroplasty was not effective for painful osteoporotic vertebral fractures. Ann Intern Med 2009;151:JC6-9

12. Kinkade S, Stevermer JJ. Vertebroplasty for osteoporotic fracture? Think twice. J Fam Pract 2009;58:654-56 